\title{
Maternal Death Surveillance and Response: Eliminating Preventable Maternal Mortality by 2030
}

\section{Eugene J Kongnyuy*}

Eugene J Kongnyuy, UNFPA, Maison Cummune des Nations Unies, Madagascar

\section{Reproductive Health Solutions, Salisbury, UK}

Worldwide, maternal deaths reduced from 542000 in 1990 and to 287000 in 2010, a decrease of $47 \%$ [1]. This does not call for immediate celebration as the reduction is slower than the international community would have wanted. Out of the eight United Nations Millennium Development Goals (MDG), the MDG 5 which targets a reduction of maternal mortality ratio by $75 \%$ between 1900 and 2015 is the one that remains the furthest from its target $[1,2]$. The current high maternal mortality reflects the week health systems in many lowincome countries.

Maternal death has been defined as the death of a woman while pregnant or within 42 days of termination of pregnancy, irrespective of the duration and site of the pregnancy, from any cause related to or aggravated by the pregnancy or its management but not from accidental or incidental causes [3]. While motherhood is often a positive and fulfilling experience, for too many women it is associated with suffering, ill-health and even death.

The high level of maternal mortality worldwide reflects inequities in access to health services, and highlights the gap between rich and poor. Developing countries account for $99 \%$ of maternal deaths; sub-Saharan Africa and Asia accounts for $85 \%$ of global maternal deaths [1]. Every day, approximately 800 women die from preventable causes related to pregnancy and childbirth. The risk of maternal death is highest among adolescent girls under 15 years old [4].

The major obstetric complication that accounts for $80 \%$ causes of maternal mortality are haemorrhage, infection, high blood pressure, unsafe abortion, and obstructed labour. The remainder are caused by or associated with diseases such as malaria and AIDS during pregnancy [5]. There are several underlying causes of maternal deaths: (a) the population, particularly women and girls are not well informed of what to do, (b) healthcare is unavailable, inaccessible or unaffordable, (c) health services are of poor quality and under-resourced, (d) traditional or informal health workers do not have the necessary skills. Other factors include poverty, child marriage, harmful cultural practices, low literacy rate and social inequality.

Although, MDG 5 is unlikely to be achieved, there is now growing consensus internationally that preventable maternal death could be eliminated by 2030 . Recent global commitments to accelerating progress in reducing maternal mortality have been encouraging. In 2010, the United Nations' Secretary General launched the Global Strategy for Women's and Children's Health which seeks to catalyse action for renewed and enhanced commitments by all partners for adequate financing and policy to improve women's and children's health [6]. In March 2012, the United Nation Commission on the Status on Women adopted a resolution calling for the elimination of preventable maternal mortality [7]. This is not an illusion, but a challenging goal which is clearly achievable given that the effective interventions to reduce preventable maternal mortality are well known.

A global consensus on these effective interventions has been reached that aims to ensure that no woman dies from preventable causes of maternal death.

These key interventions are: (a) voluntary contraception which averted $44 \%$ of maternal deaths in 2008 (272 000 maternal deaths), and meeting the unmet need for contraception could avert an additional 29\% (104 000) of maternal deaths per year [8]. (b) Skilled birth attendance whereby all deliveries are attended by a skilled health worker (midwife, physician or non-physician clinician) who has midwifery competencies to ensure that childbirth is safe. (c) life-saving Basic Emergency Obstetric and Newborn care is available when there is a complication during pregnancy, childbirth or postpartum period and should the woman need blood transfusion or Caesarean section, she is easily referred to a hospital where Comprehensive Emergency Obstetric and Newborn Care are available.

It is now recognized that the poor progress towards MDG 5 is partly due to the inability to reliably measure levels and trends of maternal mortality which in turn contributes to lack of accountability. Maternal death surveillance and response which includes maternal death identification, notification, review and response can strengthen real-time measurement and inform actions to prevent future maternal deaths [9]. Figure 1 presents the link between maternal death surveillance and the other key interventions to reduce maternal mortality and morbidity.

Maternal death surveillance and response system is designed to monitor maternal deaths both in health facility and the community and has the potential to deliver real-time, frequent monitoring of maternal mortality levels, trends and causes. Such systems should take advantage of widespread use of innovative technologies such as

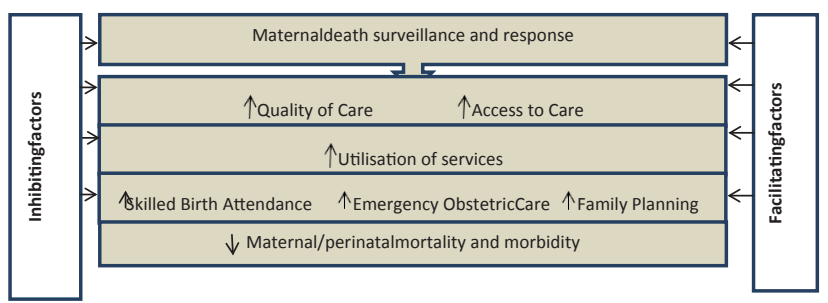

Figure 1: Linking maternal death surveillance and response and maternal/ perinatal mortality.

*Corresponding author: Eugene J Kongnyuy, UNFPA, Maison Cummune des Nations Unies, Madagascar, Tel: +441722334999; E-mail: kongnyuy73@yahoo.com

Received November 08, 2013; Accepted November 10, 2013; Published November 13, 2013

Citation: Kongnyuy (2014) Maternal Death Surveillance and Response: Eliminating Preventable Maternal Mortality by 2030. Clinics Mother Child Health 11: e102. doi: 10.4172/2090-7214.1000e102

Copyright: (c) 2014 Kongnyuy. This is an open-access article distributed under the terms of the Creative Commons Attribution License, which permits unrestricted use, distribution, and reproduction in any medium, provided the original author and source are credited. 
Citation: Kongnyuy (2014) Maternal Death Surveillance and Response: Eliminating Preventable Maternal Mortality by 2030. Clinics Mother Child Health 11: e102. doi: 10.4172/2090-7214.1000e102

Page 2 of 2

internet and mobile phones to ensure timely notification of maternal deaths. Maternal death surveillance and response systems are linked to review and action, meaning that all maternal deaths should be reviewed to identify avoidable factors and action taken to improve care at all levels of the health system, from home to hospital.

Maternal death surveillance, family planning, skilled birth attendance and Emergency Obstetric and Newborn Care are four effective interventions that if combined with health system strengthening could reduce maternal mortality ratio to below 30 per 100000 live births, the threshold where the world's preventable maternal deaths can be reasonable said to have been eliminated. We have all the tools and strategies; what is needed is action now as time is running out.

\section{References}

1. WHO, UNICEF, UNFPA, The World Bank. Trends in maternal mortality: 1990 to 2010. WHO, UNICEF, UNFPA and The World Bank estimates. Geneva: World Health Organization, 2012.
2. The Millennium Development Goals report 2011. New York: United Nations 2011.

3. WHO. Health statistics and health information systems.

4. Patton GC, Coffey C, Sawyer SM, Viner RM, et al. (2009) Global patterns of mortality in young people: a systematic analysis of population health data. Lancet 374: 881-892.

5. Khan KS, Daniel Wojdyla D, Lale Say L, Gülmezoglu AM, et al. (2006) WHO analysis of causes of maternal death: a systematic review. Lancet 367: 10661074.

6. Every Woman Every Child. UN Secretary General's Global Strategy on Women's and Children's Health.

7. UN Economic and Social Council. Commission on the Status of Women Fifty-sixth session. Eliminating maternal mortality and morbidity through the empowerment of women.

8. Ahmed S, Li Q, Liu L, Tsui AO, (2012) Maternal deaths averted by contraceptive use: an analysis of 172 countries. Lancet 380: 111-25.

9. Danel I, Graham WJ, Boerma, (2011) Maternal death surveillance and response. Bull World Health Organ 89: 779-779. 